Check for updates

Cite this: RSC Adv., 2019, 9, 30432

Received 23rd July 2019

Accepted 11th September 2019

DOI: $10.1039 / c 9 r a 05706 d$

rsc.li/rsc-advances

\section{Assembly with copper(II) ions and $D-\pi-A$ molecules on a graphene surface for ultra-fast acetic acid sensing at room temperature $\uparrow$}

\author{
Yelei Gong, $\ddagger^{a}$ Hao Li, $\ddagger^{a}$ Wenle Pei, ${ }^{b}$ Jincheng Fan, ${ }^{a}$ Ahmad Umar, ${ }^{c}$ M. S. Al-Assiri, ${ }^{c d}$ \\ Yao Wang, (iD *a Nicolaas Frans de Rooij a and Guofu Zhou ${ }^{a}$
}

In this study, a graphene-based composite $4 \mathrm{HQ}-\mathrm{rGO} / \mathrm{Cu}^{2+}$ was prepared via the supramolecular assembly of graphene nanosheets with 4-hydroxyquinoline (4HQ) and copper(॥) ions. The as-prepared supramolecular assembly exhibited an excellent and enhanced sensing performance towards acetic acid at room-temperature, which was due to the fact that the $\mathrm{D}-\pi-\mathrm{A}$ molecules, i.e. $4 \mathrm{HQ}$, were able to accelerate the charge transfer between the graphene nanosheets and $4 \mathrm{HQ}$ molecules when acetic acid was attached. In addition, at room temperature, the copper(II) ions also played a critical role as the main active site for gas adsorption, and thus the as-fabricated sensor exhibited a high response, outstanding selectivity, and ultra-fast response/recovery time. To examine the selectivity of the $\mathrm{Cu}^{2+}$ ions for the supramolecular assembly, various other transition metal ions such as $\mathrm{Mn}^{2+}, \mathrm{Fe}^{3+}, \mathrm{Co}^{2+}, \mathrm{Ni}^{2+}, \mathrm{Cu}^{2+}$, and $\mathrm{Cd}^{2+}$ were attached to the $4 \mathrm{HQ}-\mathrm{rGO}$ assembly, and their acetic sensing performance was determined. Interestingly, the supramolecular assembly with the $\mathrm{Cu}^{2+}$ ions $\left(4 \mathrm{HQ}-\mathrm{rGO} / \mathrm{Cu}^{2+}\right)$ exhibited the best sensing performance compared to other metal ion-based 4HQ-rGO materials. Compared with the typical acetic acid gas sensors reported in the literature, it is noteworthy to mention that the as-prepared $4 \mathrm{HQ}-\mathrm{rGO} / \mathrm{Cu}^{2+}$ supramolecular assembly exhibited the shortest gas response time (within $5 \mathrm{~s}$ ) at room temperature. The presented study demonstrates that the as-prepared supramolecular assembly is a promising material as a room temperature acetic acid gas sensor in practical applications.

\section{Introduction}

Acetic acid is one of the volatile organic compounds (VOCs) that is broadly used in dyes, manufacturing, photographic chemicals, and food industries. ${ }^{1,2}$ Even though it is widely used, a prolonged exposure to high concentrations of acetic acid may cause severe health hazards, such as skin irritation, body swelling, particularly on the tongue, throat, lips, face, etc., and grim breathing. ${ }^{2,3}$ Thus, developing an ultrasensitive, low-energy consuming, and reliable acetic acid gas sensor is quite important for air monitoring in modern industries. As reported, micro- and nano-metric gas sensors

${ }^{a}$ Guangdong Provincial Key Laboratory of Optical Information Materials and Technology, Institute of Electronic Paper Displays, South China Academy of Advanced Optoelectronics, South China Normal University, Guangzhou 510006, P. R. China.E-mail: wangyao@m.scnu.edu.cn

${ }^{b}$ Key Laboratory of Bio-Inspired Smart Interfacial Science and Technology of Ministry of Education, School of Chemistry, Beihang University, Beijing 100191, P. R. China

'Promising Centre for Sensors and Electronic Devices, Najran University, Najran 11001, Kingdom of Saudi Arabia

${ }^{d}$ Department of Chemistry, Faculty of Science and Arts, Najran University, Najran11001, Saudi Arabia

$\dagger$ Electronic supplementary information (ESI) available. See DOI: 10.1039/c9ra05706d

\$ These authors contributed equally to this work. based on metal-oxides exhibit excellent sensing performances at certain relatively high working temperatures although poor selectivity and high energy consumption are still a concern in research for practical applications..$^{3-6}$ Nowadays, it is still a challenge to manufacture a room-temperature gas sensor that has an excellent response to acetic acid with good selectivity and short response and recovery times.

In the past few years, graphene-based gas sensing materials have attracted considerable interest because of numerous advantages, such as a high response, short response time, low detection limit, and low working temperature (i.e., room-temperature). ${ }^{7-9}$ In addition, the distinctive morphology of graphene endues a sensitive response to small changes in an ambient environment, and the functionalization of graphene nanosheets with various "guests" (i.e., organic molecules and nanoparticles) offers a unique selectivity for the resultant gas sensors. ${ }^{10-13}$ It is known that the supramolecular assembly of graphene would retain the inherent structure of graphene and construct a better functional gas sensing scaffold..$^{\mathbf{1 4 - 1 7}}$ For example, molecules with a $\mathrm{D}-\pi-\mathrm{A}$ structure have the ability to notably improve gas sensing characteristics by enhancing the charge transfer between graphene and the assembled molecules. ${ }^{15}$ Moreover, the supramolecular assembly of graphene with "guests" can be easily conducted under mild conditions, showing promise 
for preparing commercial gas sensors. ${ }^{18}$ So far, only a few studies on graphene-based acetic acid sensors have been reported. ${ }^{19-22}$

As stated above, it is important to find a protocol to decrease the working temperature of the gas sensors. It is known that many transition metals, such as $\mathrm{V}, \mathrm{Fe}, \mathrm{Cr}$, and $\mathrm{Cu}$, show good catalytic properties under a low temperature, ${ }^{23-27}$ which implies the possibility of enhancing the charge transfer at low temperatures during the gas sensing process. Among those transition metal ions, copper is a typically widely used catalyst in the selective catalytic reduction reactions because the existence of the d-electron density of the copper ion $\left(\mathrm{Cu}^{2+}\right)$ active sites promotes charge transfer inside the material. ${ }^{24,25}$ Hence, we have a reason to propose that the presence of $\mathrm{Cu}^{2+}$ would also promote the charge transfer process inside the graphene-based composite, thereby improving the room temperature gas sensing characteristics.

In this study, we report a graphene-based sensing composite with an excellent comprehensive performance. $4 \mathrm{HQ}-\mathrm{rGO} / \mathrm{Cu}^{2+}$ was fabricated via the supramolecular assembly of graphene nanosheets with 4-hydroxyquinoline and the electrostatic adsorption of copper(II) ion. The room-temperature acetic acid sensing performance of the as-prepared composite was systematically investigated. The results revealed that the $4 \mathrm{HQ}-\mathrm{rGO} / \mathrm{Cu}^{2+}$-based acetic acid gas sensor exhibited outstanding selectivity, high sensitivity, and ultra-fast response/recovery (response and recovery times of $5 \mathrm{~s}$ each).

\section{Experimental section}

\subsection{Preparation of GO, rGO, $4 \mathrm{HQ}-\mathrm{rGO}$ and $4 \mathrm{HQ}-\mathrm{rGO} / \mathrm{Cu}^{2+}$ materials}

GO flakes (procured from XianFeng NANO Co, Ltd.) were dispersed in deionized (DI) water via a $1 \mathrm{~h}$ sonication process in order to obtain a $1 \mathrm{mg} \mathrm{mL}^{-1}$ homogeneous suspension. The rGO suspension was prepared by diluting $4 \mathrm{~mL}$ the GO suspension ( $1 \mathrm{mg} \mathrm{mL} \mathrm{mL}^{-1}$ ) with $16 \mathrm{~mL}$ DI water. Then, as a reductant, $100 \mu \mathrm{L}$ of ammonia (30\%) and $10 \mathrm{~mL}$ of hydrazine hydrate $\left(1.12 \mu \mathrm{L} \mathrm{mL}{ }^{-1}\right)$ were successively dropped into the above suspension under stirring. The mixture was placed in an oil bath $\left(85^{\circ} \mathrm{C}\right)$ and heated for $1 \mathrm{~h}$. The color change of the solution from brownish yellow to black proved the conversion of GO to rGO. To prepare the $4 \mathrm{HQ}-\mathrm{rGO}$ dispersion, $90 \mathrm{mg}$ of $4 \mathrm{HQ}$ (purchased from Alfa Aesar), $10 \mathrm{~mL}$ DI water, $4 \mathrm{~mL}$ the GO suspension, and $0.1 \mathrm{~mL}$ ammonia (30\%) were mixed to yield a homogeneous mixture. After adding $10 \mathrm{~mL}$ hydrazine hydrate under stirring, the mixture was heated at $85{ }^{\circ} \mathrm{C}$ for $1 \mathrm{~h}$. Finally, the resultant solution was washed with DI water for few times using vacuum filtration, and the obtained slurry was again redispersed in DI water $(20 \mathrm{~mL})$ under mild sonication. The $\mathrm{CuCl}_{2}$ aqueous solution $(0.5 \mathrm{~mL})$ with different $\mathrm{Cu}^{2+}$ contents was subsequently added to form a series of the $4 \mathrm{HQ}-\mathrm{rGO} / \mathrm{Cu}^{2+}$ suspension with $\mathrm{Cu}^{2+}$ concentrations of $5,10,15,20$, and $50 \mathrm{mg}$ $\mathrm{mL}^{-1}$.

\subsection{Fabrication of rGO, $4 \mathrm{HQ}-\mathrm{rGO}$ and $4 \mathrm{HQ}-\mathrm{rGO} / \mathrm{Cu}^{2+}$ based gas sensors}

Interdigitated electrodes (IDEs) were washed sequentially using DI water and acetone for 20 min under gentle sonication. The as-prepared solution was dropped on the IDEs to fabricate all the sensors, followed by a drying process. To fabricate the IDEs, $\mathrm{Ag}-\mathrm{Pd}$ paste was jetted onto the ceramic plates via a metaljetting system (10 digits with $5 \mu \mathrm{m}$ fingers and $15 \mu \mathrm{m}$ gaps, Synkera). Briefly, $30 \mu \mathrm{L}$ rGO, 4HQ-rGO, and $4 \mathrm{HQ}-\mathrm{rGO} / \mathrm{Cu}^{2+}$ suspension $\left(0.2 \mathrm{mg} \mathrm{mL}^{-1}\right)$ were assembled on the surface of the IDEs. Finally, the gas sensors were obtained after drying the coated IDEs naturally.

\subsection{Characterizations}

The characterization of the general structures for the asprepared samples was measured by field emission scanning electron microscopy (FESEM; Quanta 250 FEG, FEI). The surface structural properties were analyzed by Raman-scattering spectroscopy (HORIBA Jobin Yvon Raman microscope, LabRAM HR800) with a $647 \mathrm{~nm}$ laser line as the exciton source. The chemical compositions of the materials were examined by fourier transform infrared (FTIR; NicoletiN10MX) spectroscopy and X-ray photoelectron spectroscopy (XPS; ESCALAB250 photoelectron spectrometer, Thermo Fisher Scientific, USA).

\subsection{Gas sensing measurements}

To check the gas sensing characteristics, a CGS-1TP, ELITE TECH intelligent gas sensing system was used. The resistance variations for the as-prepared sensors were automatically detected by the system (resistance measurement range: $0 \Omega$ to 2 $\mathrm{G} \Omega$ ). Ambient air gas was aerated into two glass gas cylinders before the gas sensing measurements. Then, a quantitative acetic acid solution was injected into one of them and diffused evenly. The sensor response was defined as $\left|R_{\mathrm{a}}-R_{\mathrm{g}}\right| / R_{\mathrm{a}} \times$ $100 \%$, where $R_{\mathrm{a}}$ and $R_{\mathrm{g}}$ are the resistances of the sensing material recorded in air and the acetic acid atmosphere, respectively. Due to the ultrafast response and recovery rate, the response time was defined as the time taken for the sensor to reach its steady value. The recovery time was the time required
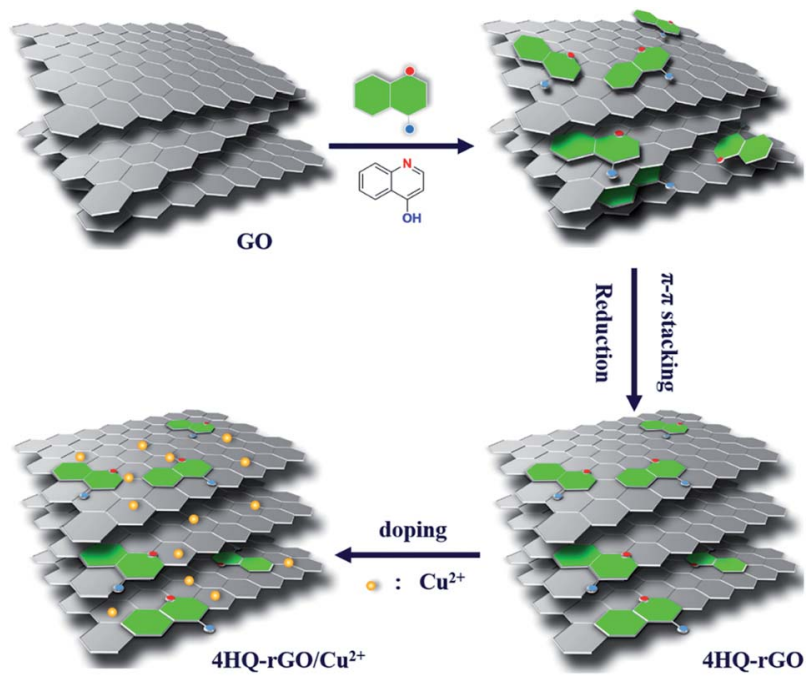

Fig. 1 A typical schematic to prepare the $4 \mathrm{HQ}-\mathrm{rGO} / \mathrm{Cu}^{2+}$ supramolecular assembly used for acetic acid gas sensor applications. 

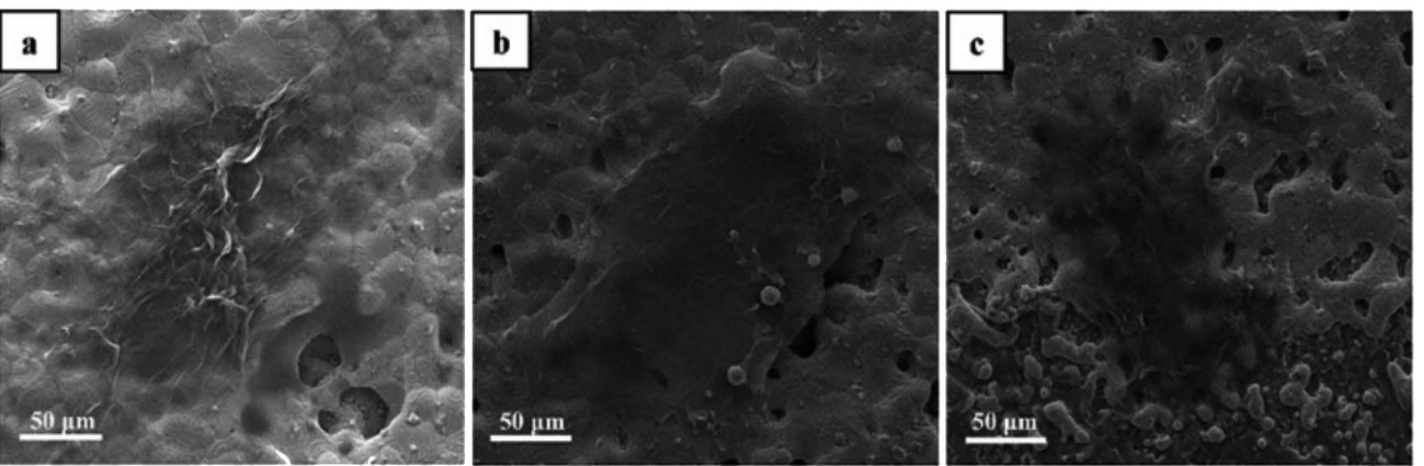

Fig. 2 Typical SEM images of (a) rGO, (b) $4 \mathrm{HQ}-\mathrm{rGO}$ and (c) $4 \mathrm{HQ}-\mathrm{rGO} / \mathrm{Cu}^{2+}$ deposited on the surface of IDEs used for acetic acid gas sensing.

for the sensor resistance to revert to its initial value. All of the gas-sensing measurements were performed at room temperature $\left(25^{\circ} \mathrm{C}\right)$ with a relative humidity $(\mathrm{RH})$ in the range of $45-$ $65 \%$.

\section{Results and discussion}

The synthesis process for $4 \mathrm{HQ}-\mathrm{rGO} / \mathrm{Cu}^{2+}$ is systematically presented in Fig. 1. First, a dipolar molecule with a $\mathrm{D}-\pi-\mathrm{A}$ structure, $4 \mathrm{HQ}$, was dispersed in the aqueous suspension of GO. After a chemical reduction with hydrazine, most of the oxygencontaining functional groups on the GO nanosheets were removed. Moreover, the $4 \mathrm{HQ}$ molecules were attached to the reduced graphene oxide (rGO) nanosheets via a supramolecular assembly driven by strong $\pi-\pi$ stacking interactions between the $4 \mathrm{HQ}$ molecules and the graphene nanosheets. Owing to the hydrophilic $-\mathrm{OH}$ group of $4 \mathrm{HQ}$, the $4 \mathrm{HQ}$ molecule-doped $\mathrm{rGO}$ possessed an exceptional dispersibility in water. Then, the copper(II) ions $\left(\mathrm{Cu}^{2+}\right)$ were introduced into the 4HQ-rGO composite by directly adding the $\mathrm{CuCl}_{2}$ solution into the $4 \mathrm{HQ}$ rGO suspension. Negatively charged graphene sheets were effectively assembled with positively charged $\mathrm{Cu}^{2+}$ due to the electrostatic adsorption..$^{28,29}$

Fig. 2 shows the representative SEM inspections of rGO, $4 \mathrm{HQ}-\mathrm{rGO}$, and $4 \mathrm{HQ}-\mathrm{rGO} / \mathrm{Cu}^{2+}$ deposited on the interdigitated electrodes (IDEs). It was observed that the wrinkled rGO nanosheets were seriously aggregated and restacked together on the IDEs (Fig. 2a), resulting in the loss of the interlaminar surface area and finally a largely reduced gas response. ${ }^{30}$ While 4HQ-rGO uniformly deposited on the IDEs (Fig. 2b) due to its excellent dispersibility in water, ${ }^{31}$ a higher specific surface area and better sensing performance were generated. After the addition of the $\mathrm{Cu}^{2+}$ solution $\left(\mathrm{CuCl}_{2}, 100 \mathrm{mg} \mathrm{mL}{ }^{-1}, 0.1-1.0 \mathrm{~mL}\right)$, no obvious morphology change for $4 \mathrm{HQ}-\mathrm{rGO}$ was found.

The changes in the chemical functional groups of asprepared 4HQ-rGO can be observed through the Fourier transform infrared (FT-IR) spectrum. As demonstrated in Fig. 3a, two characteristic bands at $\sim 3407 \mathrm{~cm}^{-1}$ and $\sim 1722 \mathrm{~cm}^{-1}$ in the GO spectra were ascribed to the hydroxy $(\mathrm{O}-\mathrm{H})$ stretching vibrations and the carboxyl $(\mathrm{C}=\mathrm{O})$ stretching vibrations of the carboxyl group of GO, respectively. A significant decrease in these two peaks in the rGO spectra reveals the successful reduction of graphene oxide. Furthermore, the observed spectrum of $4 \mathrm{HQ}-$ rGO shows the $-\mathrm{OH}$ stretching vibration at $2919 \mathrm{~cm}^{-1}$. Three characteristic peaks at $1595 \mathrm{~cm}^{-1}, 1473 \mathrm{~cm}^{-1}$, and $1061 \mathrm{~cm}^{-1}$ are attributed $\nu(\mathrm{C}=\mathrm{C}), \nu\left(\mathrm{C}_{5} \mathrm{H}_{5} \mathrm{~N}\right)$, and $\nu(\mathrm{C}-\mathrm{OH})$, respectively. The presence of these peaks in the FT-IR spectrum clearly confirmed the successful assembling of the 4HQ molecules onto the GO nanosheets.

The structural properties of the as-obtained materials were analyzed by Raman scattering spectroscopy. Two sharp peaks at $1334 \mathrm{~cm}^{-1}$ and $1592 \mathrm{~cm}^{-1}$ are attributed to the D-band and G- (a)

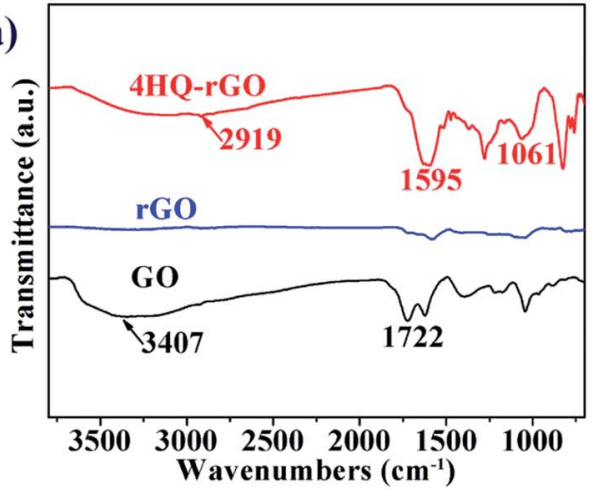

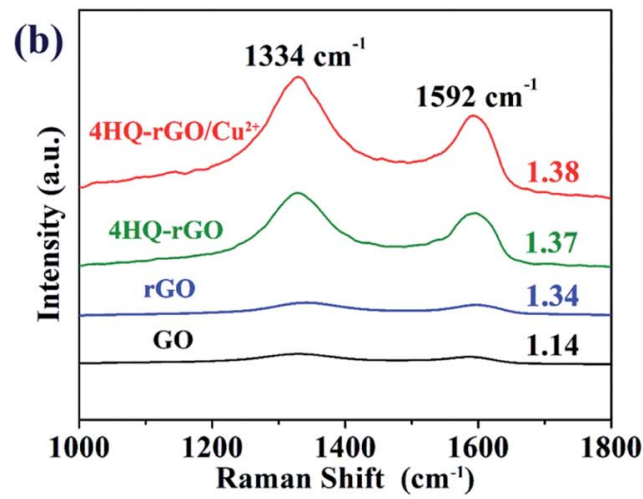

Fig. 3 (a) FT-IR spectra of the GO, rGO, and $4 \mathrm{HQ}-\mathrm{rGO}$ material. (b) Raman spectra of the $\mathrm{GO}, \mathrm{rGO}, 4 \mathrm{HQ}-\mathrm{rGO}$, and $4 \mathrm{HQ}-\mathrm{rGO} / \mathrm{Cu}{ }^{2+}$ material. 

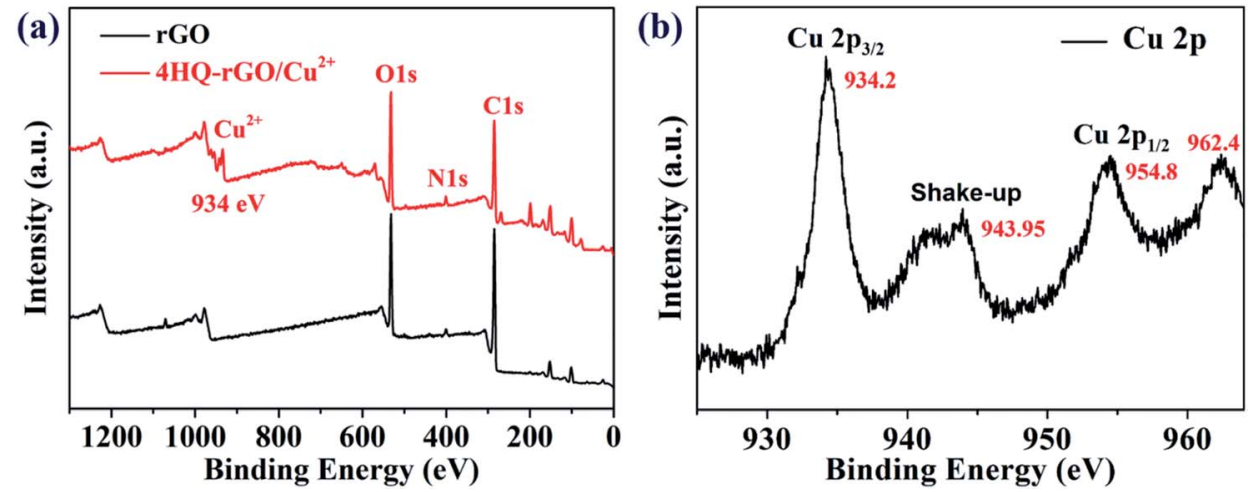

Fig. 4 (a) XPS spectra of the $\mathrm{rGO}$ and $4 \mathrm{HQ}-\mathrm{rGO} / \mathrm{Cu}^{2+}$ materials. (b) Typical XPS survey scan spectrum of Cu 2p.

band of all four samples (Fig. 3b). ${ }^{32}$ It was clear that the $I_{\mathrm{D}} / I_{\mathrm{G}}$ value for rGO (1.34), $4 \mathrm{HQ}$-rGO (1.37), along with $4 \mathrm{HQ}-\mathrm{rGO} / \mathrm{Cu}^{2+}$ (1.38) were higher than that of GO (1.14), indicating that a new $\mathrm{sp}^{2}$ cluster appeared after reduction, ${ }^{33}$ which also verified the effective reduction with hydrazine hydrate.

Furthermore, the as-prepared $\mathrm{rGO}$ and $4 \mathrm{HQ}-\mathrm{rGO} / \mathrm{Cu}^{2+}$ composites were examined by X-ray photoelectron spectroscopy (XPS) (Fig. 4a). The typical peaks for $\mathrm{N} 1 \mathrm{~s}$ appeared at $400 \mathrm{eV}$ and
$\mathrm{Cu}^{2+}$ at $934 \mathrm{eV}$ in the XPS spectrum of $4 \mathrm{HQ}-\mathrm{rGO} / \mathrm{Cu}^{2+}$, which distinctly proved that the functional $4 \mathrm{HQ}$ molecules and $\mathrm{Cu}^{2+}$ ions were successfully assembled on the rGO nanosheets. Moreover, Fig. 4b shows the typical XPS survey scan spectrum of $\mathrm{Cu} 2 \mathrm{p}$, which clearly revealed that the binding energies of $\mathrm{Cu}$ $2 \mathrm{p}_{3 / 2}$ and $\mathrm{Cu} 2 \mathrm{p}_{1 / 2}$ were located at $934.2 \mathrm{eV}$ and $954.8 \mathrm{eV}$, respectively. ${ }^{34}$ The presence of $\mathrm{Cu}^{2+}$ was confirmed by two raised characteristic peaks at 943.95 and $962.4 \mathrm{eV}{ }^{35}$ Compared to the (a)
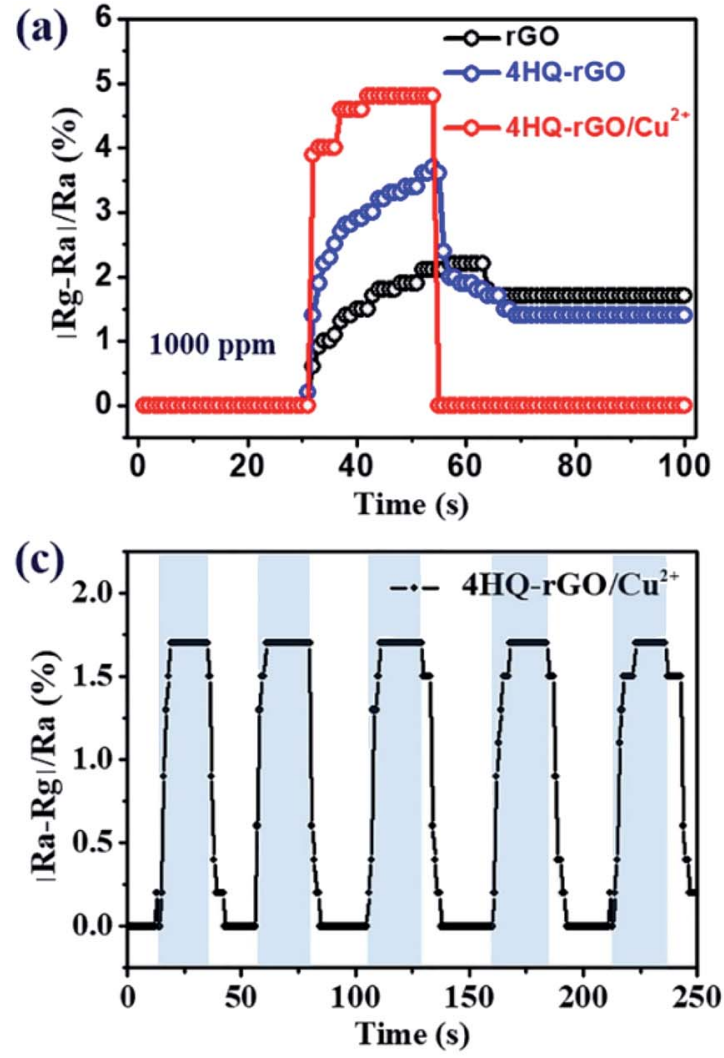

(b)

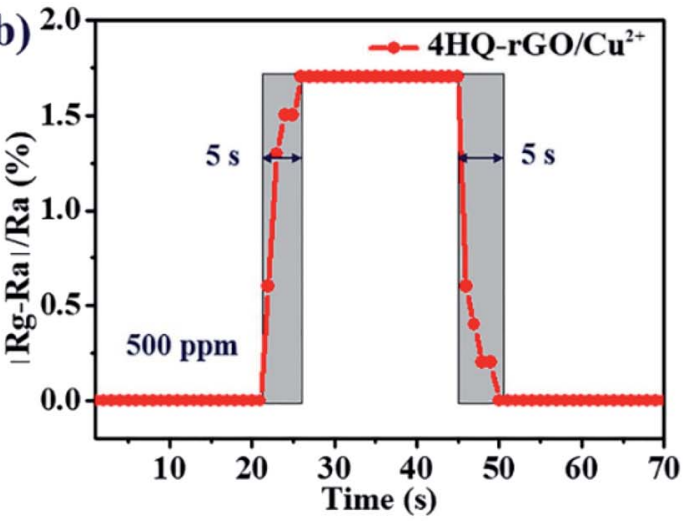

(d)

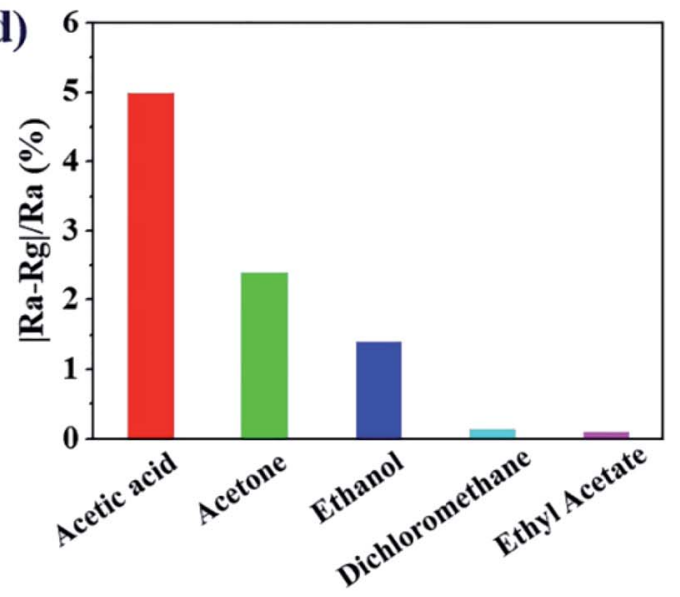

Fig. 5 (a) The typical gas sensing responses for $\mathrm{rGO}, 4 \mathrm{HQ}-\mathrm{rGO}$, and $4 \mathrm{HQ}-\mathrm{rGO} / \mathrm{Cu}^{2+}$ toward 1000 ppm acetic acid at room-temperature. (b) Response and recovery time of the $4 \mathrm{HQ}-\mathrm{rGO} / \mathrm{Cu}^{2+}$ sensing composite upon exposure to $500 \mathrm{ppm}$ acetic acid. (c) Reproducibility of the $4 \mathrm{HQ}$ $\mathrm{rGO} / \mathrm{Cu}^{2+}$ sensing composite for five successive cycles upon exposure to $500 \mathrm{ppm}$ acetic acid. (d) Selective response of the $4 \mathrm{HQ}-\mathrm{rGO} / \mathrm{Cu}^{2+}$ based sensor toward 1000 ppm acetic acid, acetone, ethanol, dichloromethane, and ethyl acetate. 
XPS spectrum of rGO, no other peaks for oxygen were observed in the survey of $4 \mathrm{HQ}-\mathrm{rGO} / \mathrm{Cu}^{2+}$, which meant that $\mathrm{Cu}$ was doped in its ionic form rather than copper oxide.

To measure the composition content in the final samples, the thermal behaviors of $4 \mathrm{HQ}-\mathrm{rGO}$ and $4 \mathrm{HQ}-\mathrm{rGO} / \mathrm{Cu}^{2+}$ were investigated using a thermal gravimetric analyzer (TGA). As shown in Fig. S3, $\dagger$ the 27 wt $\%$ weight loss before $250{ }^{\circ} \mathrm{C}$ was related to the decomposition of the $4 \mathrm{HQ}$ molecules in the survey for $4 \mathrm{HQ}-\mathrm{rGO}$. Therefore, the rGO content was $73 \mathrm{wt} \%$. The lower weight loss of $\sim 5 \mathrm{wt} \%$ in the survey for $4 \mathrm{HQ}-\mathrm{rGO} / \mathrm{Cu}^{2+}$ corresponded to the addition of $\mathrm{Cu}^{2+}$. As a result, the rGO content in the $4 \mathrm{HQ}-\mathrm{rGO} / \mathrm{Cu}^{2+}$ composites was calculated to be $59 \mathrm{wt} \%$ according to the $4 \mathrm{HQ}$ molecule content $(22 \mathrm{wt} \%)$. The content of the three compositions (i.e., $4 \mathrm{HQ}, \mathrm{rGO}$, and $\mathrm{Cu}^{2+}$ ) in the final samples was approximately $22 \mathrm{wt} \%, 59 \mathrm{wt} \%$, and $19 \mathrm{wt} \%$, respectively, based on the TGA results.

Using detailed compositional, structural and morphological characterizations, the successful assembly of the 4HQ molecules and $\mathrm{Cu}^{2+}$ ions with $\mathrm{rGO}$ nanosheets was confirmed. Thus, to explore the effect of the modification on the performance of the acetic acid sensing, the gas sensing performance of the as-prepared materials were examined in an ambient environment. The typical gas sensing response $\left(\left|R_{\mathrm{a}}-R_{\mathrm{g}}\right| / R_{\mathrm{a}} \times 100 \%\right.$, where $R_{\mathrm{a}}$ and $R_{\mathrm{g}}$ are the resistances of the sensing material recorded in air and the acetic acid atmosphere, respectively) for $\mathrm{rGO}, 4 \mathrm{HQ}-\mathrm{rGO}$, and $4 \mathrm{HQ}-\mathrm{rGO} / \mathrm{Cu}^{2+}$ are shown in Fig. 5a. It was illustrated that the responses increased when the as-prepared materials were exposed to $1000 \mathrm{ppm}$ acetic acid from the air and the responses decreased back when exposed to air atmosphere. As we expected, 4HQ-rGO exhibited a higher response, which was ascribed to the supramolecular assembly of rGO with the dipolar molecule, $4 \mathrm{HQ}$. As reported, ${ }^{36,37}$ the $\mathrm{D}-\pi-\mathrm{A}$ structure of $4 \mathrm{HQ}$ accelerated the electronic transportation between graphene and acetic acid molecules. Moreover, the introduction of the $\mathrm{Cu}^{2+}$ ions further improved the gas sensitivity and dramatically shortened the response and recovery times since the electrondeficient $\mathrm{Cu}^{2+}$ promoted the charge transfer between the small molecules and graphene nanosheets. ${ }^{38}$ It is worth noting that after switching back to the air atmosphere, the resistance for $4 \mathrm{HQ}-\mathrm{rGO} /$ $\mathrm{Cu}^{2+}$ was perfectly reverted to the initial value, unlike rGO or $4 \mathrm{HQ}-$ rGO, which was due to the low-temperature catalytic activity of the copper(II) ions. ${ }^{39}$

To further investigate the influence of the gas concentration on the response and recovery time, the $4 \mathrm{HQ}-\mathrm{rGO} / \mathrm{Cu}^{2+}$ composite was also explored toward sensing $500 \mathrm{ppm}$ acetic acid. It was demonstrated that the sensor exhibited an unique ultra-fast response-recovery characteristic toward $500 \mathrm{ppm}$ acetic acid (initial resistance: $94740 \Omega, 25{ }^{\circ} \mathrm{C}$, RH: $45 \%$ ). Both the average response and recovery times were within 5 seconds (Fig. 5b).

As stated before, sensors are required to have a high stability and selectivity in practical applications. In order to substantiate the reproducibility and stability of the prepared sensing materials, the $4 \mathrm{HQ}-\mathrm{rGO} / \mathrm{Cu}^{2+}$ based sensors were exposed to $500 \mathrm{ppm}$ acetic acid to achieve five successive response and recovery cycles (Fig. 5c). For the selectivity measurement, $1000 \mathrm{ppm}$ of various gases (i.e., acetic acid, acetone, ethanol, dichloromethane, and ethyl acetate) were chosen to examine the sensing selectivity of $4 \mathrm{HQ}-\mathrm{rGO} / \mathrm{Cu}^{2+}$ at room temperature. As illustrated in Fig. $5 \mathrm{~d}$, the $4 \mathrm{HQ}-\mathrm{rGO} / \mathrm{Cu}^{2+}$ based sensors exhibited a high sensing selectivity toward acetic acid. The excellent sensitivity and improved selectivity of the $4 \mathrm{HQ}-\mathrm{rGO} / \mathrm{Cu}^{2+}$ based sensors toward acetic acid could be explained by the band theory. ${ }^{43,44}$ The oxygen molecules were absorbed onto the surface of the graphene sheets after exposure to air atmosphere. The absorbed molecules then captured electrons from the conduction band of the graphene sheets to create an electron depletion layer $\mathrm{O}_{2}{ }^{-}$or $\left.\mathrm{O}^{-}\right){ }^{45,46}$ When transferred into acetic acid, the acetic acid molecules were oxidized by the oxygen species and the electrons captured by oxygen were thereby released to the conduction band of the graphene sheets, ${ }^{47,48}$ resulting in a lower resistance state for the sensor.

To further explore the effect of $\mathrm{Cu}^{2+}$ on the sensing properties of the $4 \mathrm{HQ}-\mathrm{rGO} / \mathrm{Cu}^{2+}$ composites, control experiments were performed with the assembly of different $\mathrm{Cu}^{2+}$ ion content and various transition metal ions that were adjacent to copper in the periodic table of elements (i.e., $\mathrm{Mn}^{2+}, \mathrm{Fe}^{3+}, \mathrm{Co}^{2+}, \mathrm{Ni}^{2+}, \mathrm{Cu}^{2+}$, and $\mathrm{Cd}^{2+}$ ). Compared with $4 \mathrm{HQ}-\mathrm{rGO}$, the response for the resultant $4 \mathrm{HQ}-\mathrm{rGO} / \mathrm{Cu}^{2+}$ suspension with a $\mathrm{Cu}^{2+}$ concentration of $5 \mathrm{mg}$ $\mathrm{mL}^{-1}$ toward $1000 \mathrm{ppm}$ acetic acid increased to $5.0 \%$ from $2.8 \%$ at room temperature, and the response and recovery times were
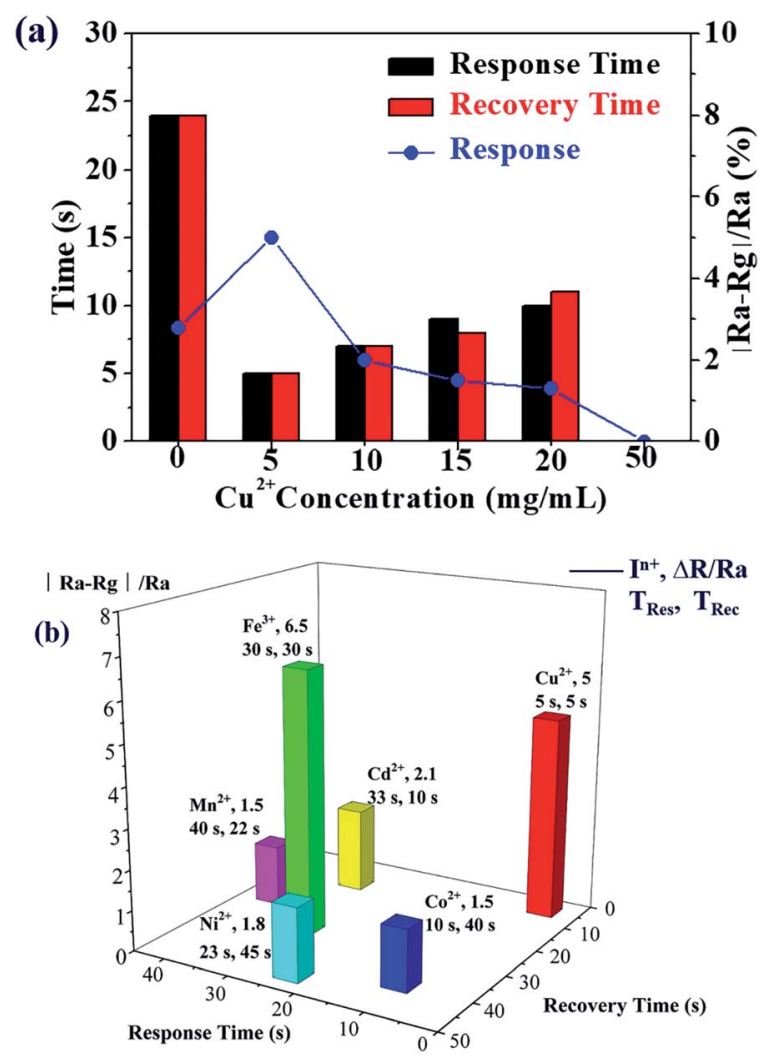

Fig. 6 (a) Typical gas sensing for the $4 \mathrm{HQ}-\mathrm{rGO} / \mathrm{Cu}^{2+}$ compositebased sensors toward $1000 \mathrm{ppm}$ acetic acid at different $\mathrm{Cu}^{2+}$ concentrations. (b) The average acetic acid gas sensing responses for the $4 \mathrm{HQ}-\mathrm{rGO}$ sensing composite doped with copper(॥) ions and other metal ions that were adjacent to copper in the periodic table of elements (i.e., $\mathrm{Mn}^{2+}, \mathrm{Fe}^{3+}, \mathrm{Co}^{2+}, \mathrm{Ni}^{2+}, \mathrm{Cu}^{2+}, \mathrm{Cd}^{2+}$, respectively). $(\Delta R=$ $\left|R_{\mathrm{a}}-R_{\mathrm{g}}\right|, T_{\text {Res }}$ : response time, and $T_{\mathrm{Rec}}$ : recovery time). 
Table 1 Comparison of the acetic acid gas sensing response and recovery time for typical sensors

\begin{tabular}{|c|c|c|c|}
\hline Materials \& structure & Acetic acid (ppm) & Operating temperature & Response time \\
\hline Mg-doped $\mathrm{ZnO} / \mathrm{rGO}^{21}$ & 100 & $250{ }^{\circ} \mathrm{C}$ & $66 \mathrm{~s}$ \\
\hline Nanosized $\mathrm{ZnO}$ particles ${ }^{22}$ & $\sim 300$ & $300^{\circ} \mathrm{C}$ & $\sim 100 \mathrm{~s}$ \\
\hline Porous flower-like $\mathrm{SnO}_{2}{ }^{41}$ & 500 & $340{ }^{\circ} \mathrm{C}$ & $11 \mathrm{~s}$ \\
\hline Coral-like and Y-doped $\mathrm{SnO}_{2}{ }^{42}$ & 500 & $300{ }^{\circ} \mathrm{C}$ & $7 \mathrm{~s}$ \\
\hline $4 \mathrm{HQ}-\mathrm{rGO} / \mathrm{Cu}^{2+}$ (this work) & 500 & Room temperature & $5 \mathrm{~s}$ \\
\hline
\end{tabular}

shortened to $5 \mathrm{~s}$ from $24 \mathrm{~s}$, respectively. However, the response value and the response and recovery times both decreased after the further increase in the $\mathrm{Cu}^{2+}$ ion content. When the concentration of $\mathrm{Cu}^{2+}$ in the $\mathrm{CuCl}_{2}$ solution increased to $50 \mathrm{mg}$ $\mathrm{mL}^{-1}$, the prepared composites even showed no response toward 1000 ppm acetic acid (Fig. 6a).

It is demonstrated in Fig. $6 \mathrm{~b}$ that the average acetic acid gas sensing responses $(R)$ for $4 \mathrm{HQ}-\mathrm{rGO}$ assembled with various transition metal ions, i.e., $\mathrm{Mn}^{2+}, \mathrm{Fe}^{3+,} \mathrm{Co}^{2+}, \mathrm{Ni}^{2+}, \mathrm{Cu}^{2+}$, and $\mathrm{Cd}^{2+}$ $\left(0.5 \mathrm{~mL}, 5 \mathrm{mg} \mathrm{mL}^{-1}\right)$ were obtained. It was obvious that the composite with the addition of $5 \mathrm{mg} \mathrm{mL}^{-1}$ of $\mathrm{Cu}^{2+}$ ions had the best sensing performance toward $1000 \mathrm{ppm}$ acetic acid $(R=5$, $T_{\text {Res }}=5 \mathrm{~s}$, and $T_{\text {Rec }}=5 \mathrm{~s}$ ) at room temperature (Fig. $6 \mathrm{~b}$ ). On one hand, it was proposed that the electron density of the copper(II) ions, which could be modulated by a mild electron-donating effect from adjacent copper ions and the nitrogen dopants of graphene, possessed an electro-catalytic activity to accelerate the gas adsorption rate. ${ }^{25}$ On the other hand, the density of the surface $\pi$-electrons of the graphene nanosheets were significantly increased due to the electron-rich and electron-deficient atom, which was in accordance with the D- $\pi-A$ structure for the $4 \mathrm{HQ}$ molecules. Therefore, the charge transfer from graphene to the $4 \mathrm{HQ}$ molecules was greatly enhanced.

The comparison of the typical acetic acid gas sensors in reported works is summarized in Table 1. It is noteworthy that only the as-prepared $4 \mathrm{HQ}-\mathrm{rGO} / \mathrm{Cu}^{2+}$ composite in this work exhibited the shortest gas response time (within $5 \mathrm{~s}$ ) at room temperature, which makes it more promising as a room temperature acetic acid gas sensor in practical applications.

\section{Conclusions}

In summary, a graphene based composite $4 \mathrm{HQ}-\mathrm{rGO} / \mathrm{Cu}^{2+}$ was prepared via the supramolecular assembly of graphene nanosheets with 4-hydroxyquinoline (4HQ) and copper(II) ions, which showed enhanced acetic acid sensing properties at room temperature. The $4 \mathrm{HQ} \mathrm{D}-\pi-\mathrm{A}$ molecules accelerated the charge transfer between the graphene nanosheets and the $4 \mathrm{HQ}$ molecules when acetic acid was attached, which is in accordance with the improved sensing properties. Moreover, the copper(II) ions also played a critical role in the main active sites during the process of adsorbing gas molecules at room temperature. The gas sensing measurement revealed that the obtained sensor possessed a high response, outstanding selectivity, and fast response-recovery time (within $5 \mathrm{~s}$ ). We believe that this study provides a promising approach to developing a highperformance acetic acid gas sensor at room temperature for applications in industry and daily life.

\section{Conflicts of interest}

The authors declare no competing financial interest.

\section{Acknowledgements}

This work was supported by the National Natural Science Foundation of China (Grant No. 51973070, No. 51673007, and No. 51773069), the Major Project of the Education Bureau of Guangdong Province, the Innovative Team Project of the Education Bureau of Guangdong Province, the Startup Foundation from SCNU, the Guangdong Provincial Key Laboratory of Optical Information Materials and Technology (Grant No. 2017B030301007), and the 111 Project. The authors would also like to acknowledge the support from the Ministry of Education, Kingdom of Saudi Arabia for this research through a grant (PCSED-004-18) under the Promising Centre for Sensors and Electronic Devices (PCSED) at Najran University, Kingdom of Saudi Arabia.

\section{References}

1 K. Khojier, Int. J. Nano Dimens., 2017, 8, 164-170.

2 Y. Tao, X. Cao, Y. Peng, Y. Liu and R. Zhang, Microchim. Acta, 2012, 176, 485-491.

3 F. Wang, H. Li, Z. Yuan, Y. Sun, F. Chang, H. Deng, L. Xie and H. Li, RSC Adv., 2016, 6, 79343-79349.

4 S. Liu, Z. Y. Wang, J. Zhang, J. Li and T. Zhang, Sens. Actuators, B, 2016, 228, 134-143.

5 J. Wei, B. Liang, Q. Cao, C. Mo, Y. Zheng and X. Ye, $R S C A d v$, 2017, 7, 33510.

6 S. Liu, Z. Wang, Y. Zhang, C. Zhang and T. Zhang, Sens. Actuators, B, 2015, 211, 318-324.

7 T. T. Tung, M. J. Nine, M. Krebsz, T. Pasinszki, C. J. Coghlan, D. N. H. Tran, et al., Adv. Funct. Mater., 2017, 27, 1702891.

8 Z. Wang, T. Han, T. Fei, S. Liu and T. Zhang, ACS Appl. Mater. Interfaces, 2018, 10, 41773-41783.

9 J. Wu, S. Feng, X. Wei, J. Shen, W. Lu, H. Shi, et al., Adv. Funct. Mater., 2016, 26, 7462-7469.

10 D. Zhang, J. Tong and B. Xia, Sens. Actuators, B, 2014, 197, 66-72. 
11 D. Zhang, D. Wang, P. Li, X. Zong and G. Dong, Sens. Actuators, B, 2018, 255, 1869-1877.

12 Z. Song, Z. Wei, B. Wang, Z. Luo, S. Xu, W. Zhang, et al., Chem. Mater., 2016, 28, 1205-1212.

13 D. Zhang, H. Chang, P. Li, R. Liu and Q. Xue, Sens. Actuators, $B, 2016,225,233-240$.

14 Z. Chen, A. Umar, S. Wang, Y. Wang, T. Tian, Y. Shang, et al., Nanoscale, 2015, 7, 10259-10266.

15 W. Pei, T. Zhang, Y. Wang, Z. Chen, A. Umar, H. Li, et al., Nanoscale, 2017, 9, 16273-16280.

16 Z. Chen, J. Wang, D. Pan, Y. Wang, R. Noetzel, H. Li, et al., ACS Nano, 2018, 12, 2521-2530.

17 S. Wang, Z. Chen, A. Umar, Y. Wang, T. Tian, Y. Shang, et al., J. Phys. Chem. C, 2015, 119, 28640-28647.

18 S. Nag, L. Duarte, E. Bertrand, V. Celton, M. Castro, V. Choudhary, et al., J. Mater. Chem. B, 2014, 2, 6571-6579.

19 X. Chu, P. Dai, Y. Dong, W. Sun, L. Bai and W. Zhang, J. Mater. Sci.: Mater. Electron., 2017, 28(24), 19164-19173.

20 J. Praneerad, N. Thongsai, P. Supchocksoonthorn, S. Kladsomboon and P. Paoprasert, Spectrochim. Acta, Part A, 2019, 211, 59-70.

21 V. Khorramshahi, J. Karamdel and R. Yousefi, Ceram. Int., 2019, 45, 7034-7043.

22 T. Prakash, R. Jayaprakash, D. Sathya Raj, S. Kumar, N. Donato, et al., Sens. Actuators, B, 2013, 176, 560-568.

23 D. Li, X. Zeng, Y. Yang, J. Yang and W. Yuan, Mater. Lett., 2012, 74, 19-21.

24 X. Wang, H. Zhang, H. Lin, S. Gupta, C. Wang, Z. Tao, et al., Nano Energy, 2016, 25, 110-119.

25 L. Chen, J. Li and M. Ge, J. Phys. Chem. C, 2009, 113, 2117721184.

26 K. Yan and A. Chen, Energy, 2013, 58, 357-363.

27 J. Wang, K. Wang, F.-B. Wang and X.-H. Xia, Nat. Commun., 2014, 5, 5285.

28 G. Yu, P. Wei, F. Wang and J. Liu, ChemElectroChem, 2017, 4, 1509-1515.

29 J. Wang, T. Wang, F. Wang, D. Zhang, K. Wang and X. Xia, J. Phys. Chem. C, 2016, 120, 15593-15599.
30 Z. Chen, J. Wang, A. Umar, Y. Wang, H. Li and G. Zhou, ACS Appl. Mater. Interfaces, 2017, 9, 11819-11827.

31 R. Jia, P. Xie, Y. Feng, Z. Chen, A. Umar and Y. Wang, Appl. Surf. Sci., 2018, 440, 409-414.

32 K. N. Kudin, B. Ozbas, H. C. Schniepp, R. K. Prud'homme, I. A. Aksay and R. Car, Nano Lett., 2008, 8, 36-41.

33 S. Stankovich, D. A. Dikin, R. D. Piner, K. A. Kohlhaas, A. Kleinhammes, Y. Jia, et al., Carbon, 2007, 45, 1558-1565.

34 R. P. Vasquez, Surf. Sci. Spectra, 1998, 5, 262-266.

35 S.-l. Gao, M. Yu, J.-h. Liu, B. Xue and S.-m. Li, Int. J. Miner., Metall. Mater., 2017, 24, 423-431.

36 O. Canbin, X. Li and A. Cao, Mater. Lett., 2015, 161, 193-196.

37 A. L. Capodilupo, E. Fabiano, L. De Marco, G. Ciccarella, G. Gigli, C. Martinelli, et al., J. Org. Chem., 2016, 81, 32353245 .

38 K. Yan, J. Liao, X. Wu and X. Xie, $R S C A d v ., 2013,3$, 38533856.

39 J. Wang, T.-T. Wang, F.-B. Wang, D.-Y. Zhang, K. Wang and X.-H. Xia, J. Phys. Chem. C, 2016, 120, 15593-15599.

40 V. Khorramshahi, J. Karamdel and R. Yousefi, J. Mater. Sci.: Mater. Electron., 2018, 29, 14679-14688.

41 T. Wang, S. Ma, L. Cheng, X. Xu, J. Luo, et al., Mater. Lett., 2015, 142, 141-144.

42 L. Cheng, S. Ma, T. Wang, J. Luo, X. Li, et al., Mater. Lett., 2014, 137, 265-268.

43 J. Zhang, F. Liao, Y. Zhu, J. Sun and M. Shao, Sens. Actuators, $B, 2015,215,497-503$.

44 V. Khorramshahi, J. Karamdel and R. Yousefi, Ceram. Int., 2019, 45, 7034-7704.

45 S. Liu, F. Hu, J. Zhang, H. Tang and M. Shao, ACS Appl. Mater. Interfaces, 2013, 5, 3208-3211.

46 L. Cheng, S. Ma, X. Li, J. Luo, W. Li, F. Li, Y. Mao, T. Wang and Y. Li, Sens. Actuators, B, 2014, 200, 181-190.

47 X. Li, Q. Zhang, S. Ma, G. Wan, F. Li and X. Xu, Sens. Actuators, B, 2014, 195, 526-533.

48 C. Wang, S. Ma, A. Sun, R. Qin, F. Yang, X. Li, F. Li and X. Yang, Sens. Actuators, B, 2014, 193, 326-333. 